\title{
Renewed Cocaine Exposure Produces Transient Alterations in Nucleus Accumbens AMPA Receptor-Mediated Behavior
}

\author{
Ryan K. Bachtell and David W. Self \\ Department of Psychiatry, University of Texas Southwestern Medical Center, Dallas, Texas 75390
}

Withdrawal from repeated cocaine is associated with increased synaptic and extrasynaptic AMPA receptor (AMPAR) expression in nucleus accumbens (NAc) neurons and enhanced behavioral sensitivity to AMPAR stimulation. Recent studies found that increased membrane expression of AMPARs is reversed or normalized on cocaine reexposure in withdrawal, but the mechanism for this AMPAR plasticity and the behavioral implications are unknown. Here, we examine the effects of renewed cocaine exposure during withdrawal on enhanced NAc AMPAR sensitivity and investigate the underlying mechanisms. Cocaine reexposure transiently reversed enhanced NAc AMPAR-mediated locomotion $1 \mathrm{~d}$ later, while enhancing cocaine-induced locomotion. Reversal in AMPAR sensitivity was prohibited by NAc AMPAR blockade with $\mathrm{CNQX}$ during cocaine reexposure and mimicked by intra-NAc infusions of AMPA, suggesting that cocaineinduced glutamate stimulation of NAc AMPARs is necessary for reversing AMPAR responsiveness. Similarly, systemic treatment with the dopamine $\mathrm{D}_{1}$-like agonist SKF 81297 [( \pm )-6-chloro-7,8-dihydroxy-l-phenyl-2,3,4,5-tetrahydro-1H-3-benzazepine hydrobromide] reversed AMPAR responsiveness in cocaine withdrawal, but the effect was prevented by local NAc AMPAR blockade in the NAc, and not local $D_{1}$-like receptor blockade, suggesting a role for glutamate afferents in the reversal of enhanced AMPAR sensitivity. Together, these findings suggest that cocaine-induced glutamate release in sensitized animals is responsible for dynamic alterations in AMPAR function that contribute to enhanced cocaine sensitivity.

Key words: glutamate; neuroplasticity; dopamine; sensitization; psychostimulant; dopamine

\section{Introduction}

Medium spiny neurons in the nucleus accumbens (NAc) undergo lasting molecular and cellular adaptations after repeated cocaine administration that contribute to behavioral changes associated with addiction (Hyman et al., 2006). Excitatory glutamate input to NAc neurons is critical in the regulation of behavioral sensitization and drug-seeking behavior (Kalivas et al., 2005; Kalivas and $\mathrm{Hu}, 2006)$. Withdrawal from repeated cocaine treatment reduces extracellular glutamate in the NAc core (Pierce et al., 1996; Bell et al., 2000), coinciding with alterations in the channel properties of NAc neurons culminating in excitability deficits (Zhang et al., 1998; Hu et al., 2004). Both of these adaptations contribute to the expression of behavioral sensitization to cocaine (Dong et al., 2006; Madayag et al., 2007).

However, other changes may reflect homeostatic adaptations to counteract deficits in excitatory neurotransmission. Thus, withdrawal from repeated cocaine treatment increases surface expression of AMPA receptor (AMPAR) subunits in the NAc (Boudreau and Wolf, 2005) and enhances AMPA-mediated synaptic currents that facilitate long-term potentiation in the NAc

Received May 4, 2008; revised 0ct. 8, 2008; accepted 0ct. 17, 2008.

This work was supported by United States Public Health Service Grants DA010460, DA18743, DA008227, and DA018481, and the Wesley Gilliland Professorship in Biomedical Research (University of Texas Southwestern Medical Center). We also thank Rachael Neve for packaging the herpes simplex vectors.

Correspondence should be addressed to Dr. Ryan K. Bachtell at his present address: Department of Psychology and Center for Neuroscience, Campus Box 345, University of Colorado, Boulder, CO 80309-0345. E-mail: Ryan.Bachtell@Colorado.edu.

DOI:10.1523/JNEUROSCI.2060-08.2008

Copyright $\odot 2008$ Society for Neuroscience $\quad$ 0270-6474/08/2812808-07\$15.00/0
(Yao et al., 2004; Boudreau and Wolf, 2005; Kourrich et al., 2007). Enhanced behavioral responses to NAc AMPA infusions also are observed 3 weeks after cessation of repeated psychostimulant treatments and are important in mediating cocaine seeking (Pierce et al., 1996; Suto et al., 2004). However, the role of these AMPAR alterations in cocaine sensitization is unclear, because they are dissociated from behavioral expression of sensitization at short ( $1 \mathrm{~d})$ and longer $(2+$ weeks) withdrawal periods (Boudreau and Wolf, 2005).

More recent evidence suggests a dynamic and complex regulation of NAc AMPARs during cocaine withdrawal. Boudreau et al. (2007) demonstrated that increases in surface expression of AMPAR subunits during cocaine withdrawal are reversed $1 \mathrm{~d}$ after reexposure to cocaine. Similarly, a cocaine challenge injection during withdrawal reverses enhanced AMPA-mediated synaptic currents and occludes long-term depression (LTD) in the NAc shell (Thomas et al., 2001; Kourrich et al., 2007). Other evidence suggests that the internalization of functional AMPARs is necessary for expression of behavioral sensitization, because preventing AMPAR endocytosis and LTD in the NAc blocks expression of behavioral sensitization to amphetamine (Brebner et al., 2005). Moreover, we found that degrading AMPAR function in the NAc increases initial cocaine sensitivity akin to cocaine sensitization (Bachtell et al., 2008). However, the mechanism underlying dynamic cocaine-induced AMPAR regulation during cocaine withdrawal, and its impact on the behavioral sensitivity to NAc AMPAR stimulation is unknown.

To assess behavioral changes associated with dynamic AM- 
Table 1. Effects of repeated saline/cocaine and challenge treatments

\begin{tabular}{|c|c|c|c|}
\hline & Day 1 & Day 7 & Challenge \\
\hline \multicolumn{4}{|c|}{ Experiment 1: Effects of cocaine challenge on AMPAR sensitization } \\
\hline Repeated saline-Veh/saline & $439.5 \pm 92.7$ & $462.4 \pm 69.7$ & $470.8 \pm 81.7$ \\
\hline Repeated saline-CNQX/saline & $493.6 \pm 68.6$ & $363.4 \pm 31.9$ & $224.6 \pm 34.7$ \\
\hline Repeated saline-Veh/cocaine & $493.3 \pm 81.2$ & $340.7 \pm 46.7$ & $1186.7 \pm 175.1^{*}$ \\
\hline Repeated saline-CNQX/cocaine & $476.3 \pm 82.1$ & $390.5 \pm 55.6$ & $1089.2 \pm 149.5^{*}$ \\
\hline Repeated cocaine-Veh/saline & $1896.5 \pm 315.1$ & $2860.5 \pm 562.1$ & $457.6 \pm 49.3$ \\
\hline Repeated cocaine-CNQX/saline & $1829.7 \pm 298.6$ & $2930.0 \pm 312.3$ & $388.3 \pm 50.0$ \\
\hline Repeated cocaine-Veh/cocaine & $1843.6 \pm 331.5$ & $2812.5 \pm 384.9$ & $2217.0 \pm 240.5^{*}$ \\
\hline Repeated cocaine-CNQX/cocaine & $1806.9 \pm 351.0$ & $2997.9 \pm 461.5$ & $1561.4 \pm 269.9^{*}$ \\
\hline \multicolumn{4}{|c|}{ Experiment 2a: Effects of increasing GluR1 on AMPAR sensitization } \\
\hline Repeated saline-HSV-LacZ/saline & $409.5 \pm 98.7$ & $462.3 \pm 59.7$ & $362.8 \pm 51.7$ \\
\hline Repeated saline-HSV-LacZ/cocaine & $352.8 \pm 115.1$ & $422.0 \pm 77.4$ & $1972.5 \pm 322.6^{*}$ \\
\hline Repeated saline-HSV-GluR1/saline & $407.5 \pm 72.0$ & $479.3 \pm 99.9$ & $327.17 \pm 82.86$ \\
\hline Repeated saline-HSV-GluR1/cocaine & $420.0 \pm 117.6$ & $513.2 \pm 117.8$ & $2305.17 \pm 452.5^{*}$ \\
\hline \multicolumn{4}{|c|}{ Experiment 2b: Effects of AMPA stimulation on AMPAR sensitization } \\
\hline Repeated cocaine-Veh/AMPA/AMPA & $1263.5 \pm 262.0$ & $2703.4 \pm 392.5$ & $506.8 \pm 41.7$ \\
\hline Repeated cocaine-AMPA/AMPA/AMPA & $1293.2 \pm 327.4$ & $2662.2 \pm 326.4$ & $1859.1 \pm 156.1^{*}$ \\
\hline \multicolumn{4}{|c|}{ Experiment 3a: Effects of dopamine agonist challenge on AMPAR sensitization } \\
\hline Repeated saline-saline & $379.6 \pm 94.7$ & $465.3 \pm 64.6$ & $435.83 \pm 61.7$ \\
\hline Repeated saline-SKF 81297 & $382.8 \pm 101.4$ & $412.0 \pm 67.2$ & $1015.3 \pm 226.8^{*}$ \\
\hline Repeated saline-quinpirole & $397.5 \pm 71.0$ & $449.3 \pm 89.9$ & $579.0 \pm 96.8$ \\
\hline Repeated cocaine-saline & $1841.0 \pm 420.2$ & $2767.2 \pm 397.5$ & $435.8 \pm 165.9$ \\
\hline Repeated cocaine-SKF 81297 & $1822.7 \pm 373.2$ & $2763.3 \pm 342.3$ & $1229.3 \pm 305.0^{*}$ \\
\hline Repeated cocaine-quinpirole & $1799.9 \pm 421.2$ & $2703.0 \pm 371.7$ & $459.9 \pm 92.5$ \\
\hline \multicolumn{4}{|c|}{ Experiment 3b: Effects of $N A c D_{1}$ receptor blockade during cocaine challenge } \\
\hline Repeated cocaine-Veh/saline & $1259.4 \pm 285.6$ & $2480.8 \pm 546.5$ & $398.3 \pm 75.65$ \\
\hline Repeated cocaine-Veh/cocaine & $1241.8 \pm 282.2$ & $2170.0 \pm 192.7$ & $1926.0 \pm 285.7^{*}$ \\
\hline Repeated cocaine-SCH 23390/cocaine & $1237.0 \pm 234.6$ & $2104.9 \pm 145.1$ & $553.4 \pm 172.2^{\wedge}$ \\
\hline \multicolumn{4}{|c|}{ Experiment 3c: Effects of NAc AMPAR blockade during $D_{1}$ agonist treatment } \\
\hline Repeated cocaine-Veh/SKF 81297 & $1578.3 \pm 284.8$ & $2653.0 \pm 214.3$ & $892.0 \pm 447.1$ \\
\hline Repeated cocaine-CNQX/ SKF 81297 & $1621.1 \pm 321.1$ & $2727.8 \pm 293.5$ & $924.8 \pm 432.8$ \\
\hline
\end{tabular}

*Post hoc comparison with respective saline or vehicle (Veh)-challenged animals. 'Post hoc comparison with respective Veh/cocaine-challenged animals ( $p<0.05$, Fisher's LSD test).

PAR plasticity, we measured the locomotor response to intraNAc infusions of AMPA either with or without cocaine reexposure $24 \mathrm{~h}$ before, when both surface and synaptic AMPAR expression are altered (Boudreau et al., 2007; Kourrich et al., 2007), and after $6 \mathrm{~d}$ to assess the recovery of AMPAR responses. We also examined the role of AMPA and dopamine receptors in mediating dynamic regulation in AMPAR function by cocaine reexposure.

\section{Materials and Methods}

Animals and housing conditions. Male Sprague-Dawley rats weighing 275-325 g (Charles River Laboratories) were individually housed with ad libitum food and water. All experiments were conducted during the light cycle $(12 \mathrm{~h})$ and in accordance with guidelines established by the National Institutes of Health and the Institutional Animal Care and Use Committee at University of Texas Southwestern Medical Center.

Intra-NAc cannulation and drug infusions. Under sodium pentobarbital anesthesia $(60 \mathrm{mg} / \mathrm{kg})$, chronic indwelling guide cannulas were stereotaxically implanted in the medial NAc core $( \pm 1.5 \mathrm{~mm}$ lateral, $1.7 \mathrm{~mm}$ anterior, and $-5.7 \mathrm{~mm}$ ventral) (Paxinos and Watson, 1998). Animals were given ketofen treatments $(5 \mathrm{mg} / \mathrm{kg}) 3 \mathrm{~d}$ postsurgery to reduce pain and inflammation, and testing began after a minimum of $6 \mathrm{~d}$ recovery. Drug microinfusions $(0.5 \mu \mathrm{l} /$ side over $100 \mathrm{~s})$ were delivered through bilateral 33 gauge injectors extending $1 \mathrm{~mm}$ beyond the guides. Herpes simplex virus (HSV) vectors encoding wild-type GluRl and LacZ (as a control) were produced and administered as described previously (Carlezon et al., 1997; Sutton et al., 2003). Testing began $48 \mathrm{~h}$ after the HSV infusion. After behavioral testing, $0.5 \mu \mathrm{l}$ of cresyl violet dye was infused in anesthetized animals before decapitation, and infusion sites localized in 0.8-mm-thick coronal slices under a dissecting microscope.
Locomotor sensitization procedure. Animals were habituated to the testing apparatus $1 \mathrm{~d}$ before repeated cocaine $(15 \mathrm{mg} / \mathrm{kg}$, i.p.; times $7 \mathrm{~d})$ or saline treatments. Horizontal locomotor activity was assessed in darkened circular test chambers (12-cm-wide runway), equipped with four pairs of photocells located at $90^{\circ}$ intervals around the $1.95 \mathrm{~m}$ perimeter. All treatments were administered in the activity monitoring chambers after a $2 \mathrm{~h}$ habituation period. Only animals meeting cocaine sensitization criterion (day 7 activity $>1.5$ times day 1 activity) were subsequently challenged and tested (85\% of animals) (Table 1).

Experiment 1: Effects of cocaine reexposure on intra-NAc AMPAR sensitivity and expression of cocaine sensitization. After repeated treatments (saline/cocaine) and home cage withdrawal (18-20 d), animals were administered intra-NAc pretreatment $(10 \% \mathrm{v} / \mathrm{v} \mathrm{DMSO} /$ saline or $0.1 \mathrm{~nm} /$ side CNQX) $5 \mathrm{~min}$ before challenge treatment (saline or 15 $\mathrm{mg} / \mathrm{kg}$ cocaine, i.p.). Twenty-four hours after treatment, animals were tested for intra-NAc AMPA $(0.2 \mathrm{nmol} / \mathrm{side})$ locomotion. Animals were retested with intra-NAc AMPA $6 \mathrm{~d}$ after the initial saline/ cocaine reexposure. Another set of cocaine-treated animals without cannulas were given either a saline or cocaine challenge $(15 \mathrm{mg} / \mathrm{kg}$, i.p.) after $18 \mathrm{~d}$ withdrawal, and tested $24 \mathrm{~h}$ later for cocaine-induced locomotion (7.5 mg/kg, i.p.).

Experiment 2a,b: Effects of increased NAc GluR1 and AMPAR stimulation on NAc AMPAR sensitivity. After repeated saline treatments and home cage withdrawal, animals received an intra-NAc infusion of HSV-LacZ or HSV-GluR1. Two days after the infusion (peak of HSVmediated expression) (Bachtell el al., 2008), animals were challenged with saline or cocaine $(15 \mathrm{mg} / \mathrm{kg}$, i.p.). Twenty-four hours after the challenge, activity was recorded after intra-NAc AMPA. Another set of animals given seven daily cocaine treatments and home cage withdrawal was challenged with either intra-NAc vehicle or AMPA $(0.2$ 
nmol/side). Twenty-four hours later, activity was recorded after an intra-NAc AMPA infusion and retested with intra-NAc AMPA $6 \mathrm{~d}$ after the initial challenge infusion.

Experiment 3a-c: Effects of dopamine $D_{1}$-like and $D_{2}$-like receptor stimulation on NAc AMPAR sensitivity. After repeated treatments (saline/cocaine) and home cage withdrawal, animals were challenged with saline, ( \pm )-6-chloro-7,8dihydroxy-1-phenyl-2,3,4,5-tetrahydro- $H$-3benzazepine hydrobromide (SKF 81297) (3.0 $\mathrm{mg} / \mathrm{kg}$, s.c.), or quinpirole (3.0 $\mathrm{mg} / \mathrm{kg}$, s.c.). Twenty-four hours later, animals were tested with intra-NAc AMPA. A separate set of cocaine-treated animals was given an intra-NAc pretreatment [vehicle or $0.1 \mu \mathrm{g} /$ side $R-(+)-7$ chloro-8-hydroxy-3-methyl-1-phenyl-2,3,4,5tetrahydro- $1 \mathrm{H}$-3-benzazepine (SCH 23390)] 5 min before a challenge (saline or cocaine) and tested with intra-NAc AMPA $24 \mathrm{~h}$ later. Other cocaine-treated animals were given intra-NAc pretreatment (vehicle or CNQX) 5 min before a challenge (saline or SKF 81297) and tested with intra-NAc AMPA $24 \mathrm{~h}$ later.

Data analysis. AMPA-mediated locomotor data (beam breaks) were analyzed by two-factor ANOVA with repeated treatment, challenge treatment, or vector treatment as the factors. Interactive effects were followed by simple main effects analyses (one-way ANOVA or $t$ tests) and post hoc tests [Fisher's least significant difference (LSD)]. Statistical significance was preset at $p<0.05$.

\section{Results}

Enhanced AMPAR responsiveness is transiently reversed by cocaine-induced glutamate release in the nucleus accumbens

We first tested the effects of cocaine reexposure on NAc AMPAR-mediated locomotion in cocaine-naive and cocainesensitized animals (Fig. 1A). Locomotor responses to intra-NAc AMPA infusions differed between repeated treatment and challenge treatment groups (interaction: $F_{(2,44)}=6.56 ; p<$ $0.005)$. Cocaine-sensitized animals administered a saline challenge during withdrawal showed increased sensitivity to NAc AMPA-induced locomotion (Fig. $1 B)\left(t_{(20)}=3.21 ; p<0.005\right.$ ), consistent with previous findings (Pierce et al., 1996). This enhancement was significantly reduced in animals reexposed to cocaine $1 \mathrm{~d}$ before the AMPA locomotor test $\left(F_{(2,22)}=4.54 ; p<\right.$ $0.05)$. Because cocaine reexposure increases glutamate release in the NAc of sensitized animals (Pierce et al., 1996; Reid and Berger, 1996), we hypothesized that cocaine-induced glutamate stimulation of AMPAR would reverse enhanced AMPAR responsiveness. Blocking NAc AMPARs during cocaine reexposure with the AMPAR antagonist CNQX prevented the subsequent reduction in AMPAR responsiveness, indicating the necessity of AMPAR stimulation for downregulating AMPAR function by cocaine. In contrast, cocaine-naive animals given acute cocaine with or without CNQX showed increased AMPA-induced activity compared with control animals $\left(F_{(2,22)}=3.85 ; p<0.05\right)$. The reduction in AMPAR responsiveness in cocaine-treated animals was transient and fully recovered $6 \mathrm{~d}$ after cocaine reexposure (Fig. $1 B$ ).
To assess how altered AMPAR sensitivity after cocaine reexposure relates to the expression of cocaine sensitization, cocainetreated animals were challenged with either saline or cocaine (15 $\mathrm{mg} / \mathrm{kg}$ ) during withdrawal. Figure $1 C$ shows that, $24 \mathrm{~h}$ later, when AMPAR sensitivity is decreased, locomotor responses to cocaine $(7.5 \mathrm{mg} / \mathrm{kg})$ were enhanced $\left(t_{(20)}=2.36 ; p<0.05\right)$. Together, these findings suggest that cocaine sensitization is clearly present when AMPAR responsiveness is increased but is further enhanced when AMPAR responsiveness is decreased. All cannulated animals used in the analysis had microinfusion sites localized medial to the anterior commissure in the NAc core (Fig. $1 D$ ) and were excluded if not meeting these bilateral accuracy requirements.

Withdrawal-like increases in GluR1 do not enable cocaineinduced regulation of AMPAR function

Given that AMPAR function is increased in cocaine withdrawal, we used viral-mediated gene transfer to increase functional GluR1 levels in the NAc of cocaine-naive animals to determine whether this neuroadaptation is sufficient to enable cocaineinduced downregulation of AMPAR function (Fig. 2A). Similar to previous findings (Bachtell et al., 2008), GluR1 overexpression 

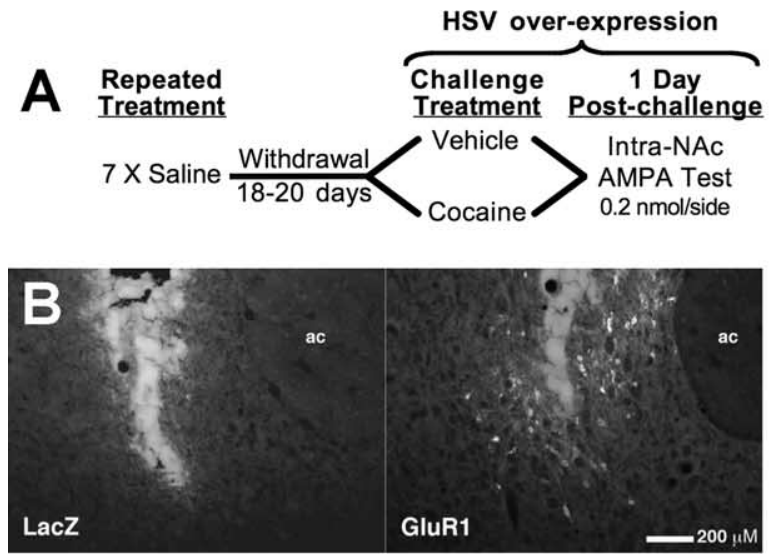
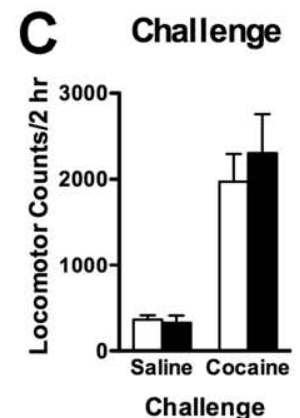

D $\begin{aligned} & \text { Repeated } \\ & \text { Treatment }\end{aligned}$
AMPA Test $1 \mathrm{~d}$ post challenge

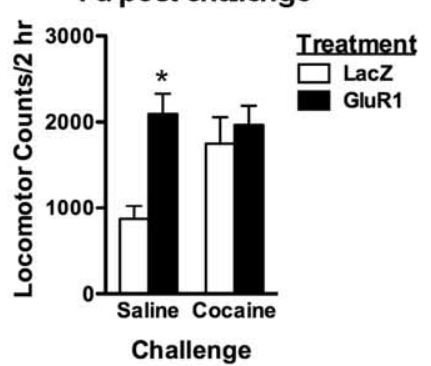

Challenge

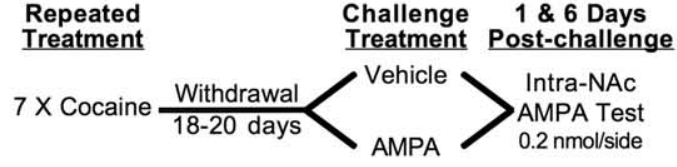

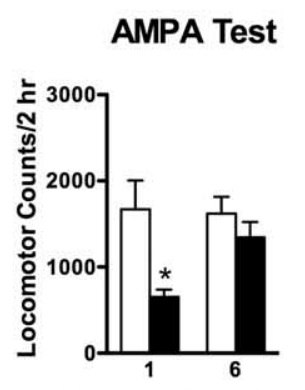

Days post challenge

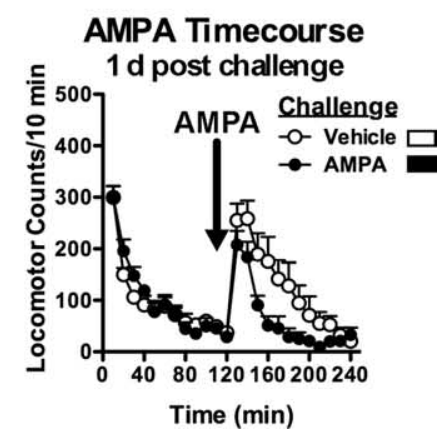

Figure 2. Stimulation of NAC AMPARs, but not GluR1 upregulation, is sufficient to reverse AMPA-induced locomotion. $\boldsymbol{A}$, Experiment outline testing the effects of GluR1 overexpression on AMPAR sensitivity. $\boldsymbol{B}$, Photomicrographs illustrating injector tracts and immunohistochemical labeling of GluR1 protein localized in the NAc core $2 \mathrm{~d}$ after HSV-GluR1 infusion (right) compared with HSV-LacZ infusion (left). ac, Anterior commissure. C, Both groups show equivalent cocaine-induced locomotion (left). GluR1 upregulation increases AMPA-induced locomotion in saline-challenged animals and is unaltered by a cocaine challenge the previous day (right). D, Experiment outline testing the sufficiency of NAC AMPAR stimulation to reduce enhanced AMPAR responses. Enhanced AMPAR sensitivity is reduced $1 \mathrm{~d}$ after intra-NAc AMPA, and normalized within $6 \mathrm{~d}$ after initial AMPAR stimulation (bottom left). Locomotor time courses are shown in bottom right panel. Data are expressed as mean ( \pm SEM) beam breaks $/ 2$ $\mathrm{h}$ ( $n=8-16 /$ group). * Post hoc comparison from LacZ or vehicle-challenged animals ( $p<$ 0.05 , Fisher's LSD test).

in NAc neurons enhanced AMPA-mediated locomotion compared with LacZ control expression in cocaine-naive animals and mimicked enhancements in AMPAR responsiveness observed in cocaine-sensitized animals (Fig. $2 B, C$ ) (interaction: $F_{(1,20)}=$ 4.51, $p<0.05$; vector: $\left.F_{(1,20)}=9.33, p<0.01\right)$. However, exog- enous enhancement in AMPAR function did not enable the ability of cocaine challenge to reduce AMPAR sensitivity when tested $1 \mathrm{~d}$ later. Thus, withdrawal-like increases in GluR1 are insufficient for dynamic regulation of AMPAR function by cocaine, consistent with a role for glutamate release in sensitized animals, or a role for other AMPAR subunits such as GluR2 in internalization mechanisms.

Stimulation of NAc AMPARs is sufficient to reverse enhanced AMPAR responsiveness

Because the ability of cocaine to reverse enhanced AMPAR responsiveness was prevented by AMPAR blockade, we tested whether direct AMPAR stimulation would mimic the reversal in cocaine-sensitized animals (Fig. 2D). Stimulation of AMPARs produced a transient reduction in AMPAR sensitivity after $1 \mathrm{~d}$ $\left(F_{(1,20)}=8.53 ; p<0.01\right)$ that fully recovered $6 \mathrm{~d}$ after the initial AMPA treatment (interaction: $F_{(1,20)}=4.39 ; p<0.05$ ). These results suggest that glutamate stimulation of NAc AMPARs during cocaine challenge in cocaine-sensitized animals is sufficient to regulate functional AMPARs.

Dopamine $D_{1}$-like stimulation transiently reverses enhanced AMPAR responsiveness through NAc AMPAR stimulation Cocaine reexposure in sensitized animals also elevates extracellular dopamine levels that stimulate dopamine $D_{1}$ and $D_{2}$ receptors. We tested the ability of the dopamine agonists SKF $81297\left(\mathrm{D}_{1}\right.$-like $)$ and quinpirole $\left(\mathrm{D}_{2}\right.$-like $)$ to modulate enhanced AMPAR responsiveness in cocaine withdrawal (Fig. 3A). Challenge treatment with SKF 81297 and quinpirole differentially altered AMPAR-mediated locomotion in salineand cocaine-treated animals (interaction: $F_{(2,64)}=7.233, p<$ $0.002)$. In cocaine-treated animals, systemic challenge with SKF 81297, but not quinpirole, reversed enhanced AMPAR responsiveness the following day $\left(F_{(2,29)}=4.15 ; p<0.001\right)$, suggesting that cocaine-induced elevations in dopamine and $\mathrm{D}_{1}$ receptor stimulation in the NAc may contribute to alterations in AMPAR sensitivity. In contrast, both SKF 81297 and quinpirole challenge enhanced AMPAR sensitivity in salinetreated animals $\left(F_{(2,34)}=4.03 ; p<0.02\right)$.

To determine whether NAc $D_{1}$ receptors regulate AMPAR responsiveness with cocaine reexposure, cocaine-sensitized animals were given an intra-NAc pretreatment with the $\mathrm{D}_{1}$ receptor antagonist SCH 23390 before cocaine challenge in cocaine withdrawal (Fig. 3B). Surprisingly, intra-NAc SCH 23390 during cocaine reexposure failed to prevent the reversal of enhanced AMPAR responsiveness the following day $\left(F_{(2,18)}=4.00 ; p<0.05\right)$, despite the fact that it completely attenuated cocaine-induced locomotion during the challenge treatment $\left(F_{(2,18)}=18.13 ; p<0.001\right)$.

Because the $\mathrm{D}_{1}$ agonist was administered systemically, we hypothesized that $D_{1}$ receptor stimulation of glutamate afferents to the NAc is involved in $\mathrm{D}_{1}$-induced reversal of enhanced AMPAR responsiveness. In cocaine-sensitized animals, pretreatment with intra-NAc CNQX before systemic SKF 81297 treatment prevented the reversal of enhanced AMPAR responsiveness the following day (Fig. $3 C)\left(F_{(1,27)}=2.00 ; p<0.01\right)$. The reversal by SKF 81297 challenge treatment alone recovered $6 \mathrm{~d}$ after challenge $\left(F_{(1,27)}=4.07 ; p=0.05\right)$.

\section{Discussion}

Our findings demonstrate that cocaine reexposure after a drug-free period reduces the behavioral response to NAc AMPAR stimulation. These data provide in vivo functional evidence for the behavioral significance of dynamic redistri- 
bution of cell surface and synaptic AMPAR expression (Thomas et al., 2001; Boudreau et al., 2007; Kourrich et al., 2007). Additionally, such dynamic reductions in AMPAR function are transient, rebounding within days. The reversal of enhanced AMPAR responsiveness by cocaine reexposure or $\mathrm{D}_{1}$ like agonist challenge requires NAc glutamate release in concert with NAc AMPAR stimulation, and local AMPAR stimulation alone is sufficient to transiently mimic the reversal.

Our behavioral data agree with studies showing that enhanced postsynaptic AMPAR function is reversed after cocaine reexposure (Kourrich et al., 2007), suggesting endocytosis of functional AMPARs (Boudreau et al., 2007). Our data also suggest that AMPAR endocytosis with cocaine reexposure results from cocaine-induced glutamate release that occurs only after repeated cocaine exposure (Pierce et al., 1996; Reid and Berger, 1996). Stimulation of AMPA receptors rapidly internalizes AMPARs in cultured neurons (Lissin et al., 1999; Mangiavacchi and Wolf, 2004) and contributes to LTD induction (Carroll et al., 1999). Relevant to the present study, antagonist blockade of AMPARs partially blocked glutamate-induced AMPAR internalization in culture NAc neurons (Mangiavacchi and Wolf, 2004). In our studies, NAc AMPAR blockade prevents cocaine-induced reversal of enhanced AMPAR responsiveness, whereas stimulation of NAc AMPAR mimics the reversal in AMPAR responses after cocaine reexposure. Together, these findings suggest that a cocaine-induced surge in NAc glutamate and AMPAR stimulation leads to AMPAR internalization and loss of functional AMPARs.

Cocaine reexposure in sensitized animals also causes dopamine release and dopamine receptor stimulation in terminal regions such as the NAc, cortex, and limbic regions. Selective $\mathrm{D}_{1}$-like, but not $\mathrm{D}_{2}$-like, receptor stimulation recapitulates reduced AMPAR responsiveness produced by cocaine reexposure. Similar to cocaine, the $\mathrm{D}_{1}$-induced reduction in AMPAR responsiveness was prohibited by NAc AMPAR blockade, suggesting that $\mathrm{D}_{1}$ stimulation activates glutamate projections to the NAc. The prefrontal cortex is a likely candidate given its role in sensitization processes (Steketee, 2005). Interestingly, acute $D_{1}$ receptor stimulation in cocultured corticalaccumbens neurons increases membrane expression of AMPARs (Sun et al.,
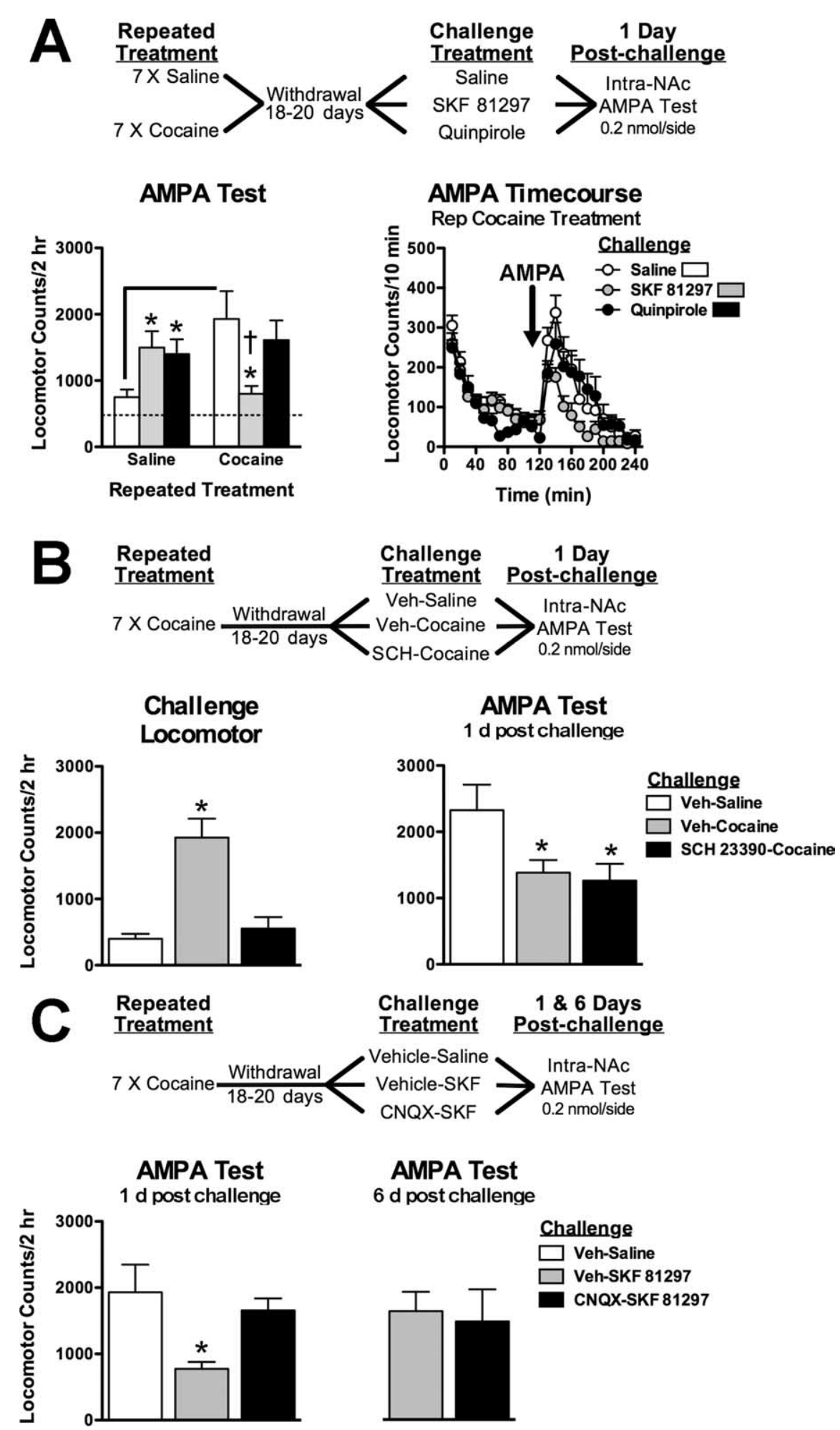

Figure 3. Dopamine $D_{1}$ receptor stimulation reduces enhanced AMPAR responses through NAc AMPAR stimulation. $A$, Experiment outline testing the effects of $D_{1} / D_{2}$ receptor stimulation on enhanced AMPAR sensitivity. SKF 81297 (3 mg/kg, s.c.) and quinpirole $\left(3 \mathrm{mg} / \mathrm{kg}\right.$, s.c.) treatments increase AMPAR-induced locomotion in cocaine-naive animals after $1 \mathrm{~d}$, but $D_{1}$ receptor stimulation reverses enhanced AMPAR responses in cocaine-treated animals. $\boldsymbol{B}$, Experiment outline testing the necessity of NACD receptor stimulation for cocaine-induced reversal enhanced AMPAR sensitivity. Intra-NAc infusion with SCH $23390(0.1 \mu \mathrm{g} / \mathrm{side})$ blocks cocaine-induced locomotion during challenge treatment (bottom left) but has no effect on subsequent cocaine-induced reversal of AMPAR sensitivity (bottom right). $C$, Experiment outline testing the necessity of NACAMPAR stimulation for $D_{1}$-induced reversal of enhanced AMPAR sensitivity. $D_{1}$-induced reversal of AMPAR sensitivity is prevented by intra-NAC CNQX. Data are expressed as mean ( \pm SEM) beam breaks/2 h ( $n=6-12 /$ group). The solid line differs from repeated saline/saline challenge controls and $(\dagger)$ differs from repeated saline/SKF 81297 challenged group ( $p<0.05, t$ test). ${ }^{*}$ Post hoc comparison from respective Veh-saline or Veh-SKF 81297 challenged animals ( $p<0.05$, Fisher's LSD test). 
2008), and a similar local phenomenon could underlie enhanced AMPAR sensitivity after $\mathrm{D}_{1}$ stimulation (Fig. 3) or initial cocaine exposure (Fig. 1) in saline-treated animals in our study. After repeated dopamine stimulation, the ability of $\mathrm{D}_{1}$ stimulation to enhance surface AMPARs is lost because of $D_{1}$ receptor internalization in NAc neurons (Sun et al., 2008). With a localized loss of $\mathrm{D}_{1}$-regulated AMPAR expression in NAc neurons after cocaine sensitization, the effects of $D_{1}$ receptor stimulation on cortical glutamatergic afferents may prevail, leading to reduced rather than enhanced AMPAR expression.

The functional role of NAc AMPAR redistribution in the behavioral expression of cocaine sensitization is not completely understood. Internalization of NAc AMPAR is necessary for the expression of amphetamine sensitization, because sensitized responses are prevented by intra-NAc infusion of a peptide interfering with AMPAR internalization (Brebner et al., 2005). However, increased surface AMPAR expression is not observed after withdrawal from repeated amphetamine (Nelson et al., 2006). We recently found that mimicking the internalization-induced loss of functional AMPAR in cocaine-naive animals is sufficient to increase initial behavioral sensitivity to cocaine and a $\mathrm{D}_{2}$ dopamine receptor agonist (Bachtell et al., 2008). Thus, the expression of cocaine sensitization may result from rapid degradation in endogenous AMPAR function because of AMPAR endocytosis that facilitates behavioral responses to concomitant elevations in dopamine during cocaine reexposure. The present study suggests that without enhanced NAc glutamate release and AMPAR stimulation, degradation in AMPAR function does not occur, consistent with the ability of AMPAR blockade to attenuate the expression of cocaine sensitization (Pierce et al., 1996). This reliance on a surge in glutamate release in cocaineexperienced animals is also supported by the fact that upregulating AMPAR function in cocaine-naive animals does not alter cocaine sensitivity and does not enable cocaine-induced reductions in AMPAR responses.

Alternatively, it is possible that changes in AMPAR distribution and function are unrelated to the expression of cocaine sensitization. Changes in the cellular distribution of AMPARs are dissociated from the behavioral expression of sensitization at short ( $1 \mathrm{~d}$ ) and longer ( $2+$ weeks) withdrawal periods (Boudreau and Wolf, 2005). Additionally, we found that cocaine sensitization is observed when AMPAR responses are increased and further enhanced after cocaine reexposure when AMPAR responses are decreased. Therefore, although changes in NAc AMPAR number and function may modulate the expression of cocaine sensitization, they may not underlie the fundamental mechanisms of cocaine sensitization.

It appears that plasticity at both the cellular and systems level resulting from repeated cocaine exposure and withdrawal are important to enable regulation of AMPAR function; however, the contribution of AMPAR plasticity in the NAc to cocaine addiction is unclear. Pharmacological stimulation of NAc AMPARs elicits cocaine seeking in extinguished animals (Cornish and Kalivas, 2000; Suto et al., 2004), whereas increases in NAc AMPAR levels are associated with either attenuation (Sutton et al., 2003; Levy et al., 2007; Bachtell et al., 2008) or enhancement in cocaine seeking (Conrad et al., 2008). AMPAR-mediated transmission in the NAc is certainly important in the expression of drug seeking, but whether it is promoted by AMPAR excitation of NAc neurons, the subsequent rapid AMPAR internalization, or the combined biphasic effect is unknown. Together, these findings high- light the importance and complexity of dynamic regulation of AMPAR function in the NAc in cocaine addiction.

\section{References}

Bachtell RK, Choi KH, Simmons DL, Falcon E, Monteggia LM, Neve RL, Self DW (2008) Role of GluR1 expression in nucleus accumbens neurons in cocaine sensitization and cocaine-seeking behavior. Eur J Neurosci 27:2229-2240.

Bell K, Duffy P, Kalivas PW (2000) Context-specific enhancement of glutamate transmission by cocaine. Neuropsychopharmacology 23:335-344.

Boudreau AC, Wolf ME (2005) Behavioral sensitization to cocaine is associated with increased AMPA receptor surface expression in the nucleus accumbens. J Neurosci 25:9144-9151.

Boudreau AC, Reimers JM, Milovanovic M, Wolf ME (2007) Cell surface AMPA receptors in the rat nucleus accumbens increase during cocaine withdrawal but internalize after cocaine challenge in association with altered activation of mitogen-activated protein kinases. J Neurosci 27:10621-10635.

Brebner K, Wong TP, Liu L, Liu Y, Campsall P, Gray S, Phelps L, Phillips AG, Wang YT (2005) Nucleus accumbens long-term depression and the expression of behavioral sensitization. Science 310:1340-1343.

Carlezon WA Jr, Boundy VA, Haile CN, Lane SB, Kalb RG, Neve RL, Nestler EJ (1997) Sensitization to morphine induced by viral-mediated gene transfer. Science 277:812-814.

Carroll RC, Lissin DV, von Zastrow M, Nicoll RA, Malenka RC (1999) Rapid redistribution of glutamate receptors contributes to long-term depression in hippocampal cultures. Nat Neurosci 2:454-460.

Conrad KL, Tseng KY, Uejima JL, Reimers JM, Heng LJ, Shaham Y, Marinelli M, Wolf ME (2008) Formation of accumbens GluR2-lacking AMPA receptors mediates incubation of cocaine craving. Nature 454:118-121.

Cornish JL, Kalivas PW (2000) Glutamate transmission in the nucleus accumbens mediates relapse in cocaine addiction. J Neurosci 20:RC89(1-5).

Dong Y, Green T, Saal D, Marie H, Neve R, Nestler EJ, Malenka RC (2006) CREB modulates excitability of nucleus accumbens neurons. Nat Neurosci 9:475-477.

Hu XT, Basu S, White FJ (2004) Repeated cocaine administration suppresses HVA-Ca ${ }^{2+}$ potentials and enhances activity of $\mathrm{K}^{+}$channels in rat nucleus accumbens neurons. J Neurophysiol 92:1597-1607.

Hyman SE, Malenka RC, Nestler EJ (2006) Neural mechanisms of addiction: the role of reward-related learning and memory. Annu Rev Neurosci 29:565-598.

Kalivas PW, Hu XT (2006) Exciting inhibition in psychostimulant addiction. Trends Neurosci 29:610-616.

Kalivas PW, Volkow N, Seamans J (2005) Unmanageable motivation in addiction: a pathology in prefrontal-accumbens glutamate transmission. Neuron 45:647-650.

Kourrich S, Rothwell PE, Klug JR, Thomas MJ (2007) Cocaine experience controls bidirectional synaptic plasticity in the nucleus accumbens. J Neurosci 27:7921-7928.

Levy D, Shabat-Simon M, Shalev U, Barnea-Ygael N, Cooper A, Zangen A (2007) Repeated electrical stimulation of reward-related brain regions affects cocaine but not "natural" reinforcement. J Neurosci 27:14179-14189.

Lissin DV, Carroll RC, Nicoll RA, Malenka RC, von Zastrow M (1999) Rapid, activation-induced redistribution of ionotropic glutamate receptors in cultured hippocampal neurons. J Neurosci 19:1263-1272.

Madayag A, Lobner D, Kau KS, Mantsch JR, Abdulhameed O, Hearing M, Grier MD, Baker DA (2007) Repeated N-acetylcysteine administration alters plasticity-dependent effects of cocaine. J Neurosci 27:13968-13976.

Mangiavacchi S, Wolf ME (2004) Stimulation of N-methyl-D-aspartate receptors, AMPA receptors or metabotropic glutamate receptors leads to rapid internalization of AMPA receptors in cultured nucleus accumbens neurons. Eur J Neurosci 20:649-657.

Nelson CL, Milovanovic M, Wolf ME (2006) Characterization of glutamate receptor trafficking and signal transduction in the nucleus accumbens following repeated amphetamine administration. Soc Neurosci Abstr 32:394.6.

Paxinos G, Watson C (1998) The rat brain in stereotaxic coordinates, Ed 4. San Diego: Academic.

Pierce RC, Bell K, Duffy P, Kalivas PW (1996) Repeated cocaine augments excitatory amino acid transmission in the nucleus accumbens only in rats having developed behavioral sensitization. J Neurosci 16:1550-1560.

Reid MS, Berger SP (1996) Evidence for sensitization of cocaine-induced nucleus accumbens glutamate release. Neuroreport 7:1325-1329. 
Steketee JD (2005) Cortical mechanisms of cocaine sensitization. Crit Rev Neurobiol 17:69-86.

Sun X, Milovanovic M, Zhao Y, Wolf ME (2008) Acute and chronic dopamine receptor stimulation modulates AMPA receptor trafficking in nucleus accumbens neurons cocultured with prefrontal cortex neurons. J Neurosci 28:4216-4230.

Suto N, Tanabe LM, Austin JD, Creekmore E, Pham CT, Vezina P (2004) Previous exposure to psychostimulants enhances the reinstatement of cocaine seeking by nucleus accumbens AMPA. Neuropsychopharmacology 29:2149-2159.

Sutton MA, Schmidt EF, Choi KH, Schad CA, Whisler K, Simmons D, Karanian DA, Monteggia LM, Neve RL, Self DW (2003) Extinction-induced upregulation in AMPA receptors reduces cocaine-seeking behaviour. Nature $421: 70-75$.

Thomas MJ, Beurrier C, Bonci A, Malenka RC (2001) Long-term depression in the nucleus accumbens: a neural correlate of behavioral sensitization to cocaine. Nat Neurosci 4:1217-1223.

Yao WD, Gainetdinov RR, Arbuckle MI, Sotnikova TD, Cyr M, Beaulieu JM, Torres GE, Grant SG, Caron MG (2004) Identification of PSD-95 as a regulator of dopamine-mediated synaptic and behavioral plasticity. Neuron 41:625-638.

Zhang XF, Hu XT, White FJ (1998) Whole-cell plasticity in cocaine withdrawal: reduced sodium currents in nucleus accumbens neurons. J Neurosci 18:488-498. 